\title{
INFLUENCE OF LASER TEXTURING ON TRIBOLOGICAL PROPERTIES OF TOOL MATERIALS
}

\author{
${ }^{1}$ Daniel PAKUŁA, ${ }^{1}$ Marcin STASZUK, ${ }^{1}$ Magdalena WAWRZYCZEK, ${ }^{2}$ Pavel KOŽMíN, \\ ${ }^{2}$ Adam ČERMÁK
}

\author{
${ }^{1}$ Silesian University of Technology, Institute of Engineering Materials and Biomaterials, \\ Gliwice, Poland, EU, daniel.pakula@polsl.pl \\ ${ }^{2}$ HOFMEISTER s.r.o., Pilsen, Czech Republic, EU, kozmin@hofmeister.cz
}

https://doi.org/10.37904/metal.2019.888

\begin{abstract}
This paper presents the influence of laser texturing on the tribological properties of sintered tool materials not coated and coated in the process of chemical deposition from the gas phase. Sintered carbide substrate, sialon ceramics substrate and the $\mathrm{Al}_{2} \mathrm{O}_{3}+\mathrm{TiN}$ coating deposited on sialon ceramic substrate were subjected to laser treatment. Neodymium laser Nd: YVO4 was used for laser texturing. The work presents abrasion resistance tests using the "pin on disc" method. The examinations were carried out using a scanning electron microscope (SEM), surface morphology - using atomic force microscope (AFM), confocal microscope and optical profilometer. The chemical composition in micro-areas was also examined by the use of the EDS X-ray energy spectrometer, roughness and abrasion profiles were measured. Subjecting laser treatment, the surface of tool materials, results in changing the micro and nano structure. In the micro scale, so-called lubrication reservoirs, while in the nano scale, so-called nanoripples commonly referred to as LIPSS (Laser Induced Periodical Surface Structures) are created. The value of the friction coefficient ranged from 0.7 for laser-free non-textured surfaces to 0.4 for laser-textured surfaces. As a result of the tests carried out, it was found that the creation of a textured surface layer in micro and nano scale, resulted in a significant increase of tool materials wear resistance.
\end{abstract}

Keywords: Laser texturing, LIPSS, Tool materials, CVD

\section{INTRODUCTION}

Increasing the durability of the cutting tool blades is constantly arousing interest among scientists from around the world. In addition to the classic methods of tool materials surface treatment, which include technologies physical deposition from the gas phase PVD and chemical CVD deposition [1-4], attention has recently been focused on laser surface texturing in which a laser beam with high energy density is used in methodical designing of tool surfaces [5]. In laser texturing process, a laser with high pulses frequency and with high coefficient of repeatability, causes changes in the structure by local surface melting. After solidification of melted surface, its microstructural and nanostructural special topography is created. Nowadays many parts of machines and equipment require a specially designed surface with a carefully planned roughness, on which the properties of the surface layer depend. Depending on roughness depth and frequency, material can have completely different properties, both tribological and optical, or changing the wettability of the surface layer. There are many different methods for achieving correct texture, i.e. a privileged arrangement of crystallites in the material surface layer. One of such structures is laser-induced periodic surface structures, also known as LIPSS, which was discovered in 1965, however, for a long time it was only a scientific curiosity and only recently wider studies on the practical application of this structure has begun [6-12].

Laser texturing of tool materials is also used in the substrate preparation for the application of soft lubricating coatings (eg $\mathrm{MoS}_{2}, \mathrm{WS}_{2}$ ). This treatment may partially minimize the problems associated with maintaining a constant layer of grease for the lifetime, poor adhesion, difficulties in replenishing and poor thermal conductivity of these coatings [6-8]. Researches are also being carried out on the effect of the laser-textured surface of tool 
materials on the functional properties of tools without coatings. In [9] computer simulation of various types of texture (in the shape of a circle, ellipse, square and triangle) of cemented carbides was carried out in the treatment of titanium alloys. It has been shown that the greatest decrease in friction force occurs with a circular shape. In other studies [10] both the face tool surface and the tool relief surface were textured and used during face milling of AISI 1053 steel. Crater reduction was achieved as well as a drastic wear reduction of relief surface. Both laser texturing of materials exposed to intensive tribological contact during work and the texturing of tool materials before application of anti-wear and lubricating coatings is the subject of intensive researches, however, the least literature reports concern the application of laser texturing of coating surfaces after their deposition [6]. Hard coatings (e.g., (Ti,Al)N) are usually characterized by a high friction coefficient during the machining process, which can cause their accelerated wear. An alternative to the methods used to reduce the friction coefficient, such as cutting fluids or cryogenic treatment, can be laser texturing of coating surface. The textured coating surface also contributes to the occurrence of beneficial physical mechanisms during coating operating [8].

The paper presents the effect of laser texturing on the tribological properties of sintered tool materials (cemented carbides and sialon ceramics) without coating and tool ceramics with $\mathrm{TiN}+\mathrm{Al}_{2} \mathrm{O}_{3}$ coating.

\section{MATERIALS AND METHODOLOGY}

The examinations were carried out on cutting plates made of cemented carbides $\mathrm{H} 10$, sialon ceramics and on the $\mathrm{Al}_{2} \mathrm{O}_{3}+\mathrm{TiN}$ coating deposited on the tool ceramics in CVD chemical vapor deposition process. A neodymium laser Nd: YVO4 was used for laser texturing of tested tool materials. Table 1 shows the typical parameters of this laser.

Table 1 Typical parameters on neodymium laser Nd: YVO4

\begin{tabular}{|c|c|c|}
\hline Device type & \multicolumn{2}{|c|}{ DPSS Nd: YVO4 } \\
\hline$\lambda$ & $1064 \mathrm{~nm}$ & $532 \mathrm{~nm}$ \\
\hline$f_{p}$ & \multicolumn{2}{|c|}{$200-1000 \mathrm{kHz}$} \\
\hline $\mathrm{P}$ & $>20 \mathrm{~W}(\mathrm{fp}=200 \mathrm{kHz})$ & $>12 W \quad(\mathrm{fp}=200 \mathrm{kHz})$ \\
\hline $\mathrm{T}$ & \multicolumn{2}{|c|}{$<13 p s$} \\
\hline Spatial mod TEM00, Parameter $\mathrm{M}^{\wedge} 2$ & \multicolumn{2}{|c|}{$<1.3$} \\
\hline Focusing lens & \multicolumn{2}{|c|}{ Telecentric } \\
\hline$f$ (focusing lenght.) & \multicolumn{2}{|c|}{$130 \mathrm{~mm}$} \\
\hline working field of scanning head & \multicolumn{2}{|c|}{$45 \times 45 \mathrm{~mm}$} \\
\hline
\end{tabular}

Scanning electron microscope Zeiss Supra 35 was used to observe both the structure and morphology of the obtained surface layers as well as surface damages resulting from carried out tribological tests. A chemical composition analysis in micro-areas was made with the Energy Dispersive Spectrometry (EDS) method.

Tribological tests were carried out on the CSEM „pin-on-disc” tester under following conditions: counter-sample - ball made from the $\mathrm{Al}_{2} \mathrm{O}_{3}$ aluminum oxide with $6 \mathrm{~mm}$ diameter, counter-sample load - $5 \mathrm{~N}$, friction radius - 5 $\mathrm{mm}$, linear velocity $-0.1 \mathrm{~m} / \mathrm{sec}$, ambient temperature $-20^{\circ} \mathrm{C}$.

For the analysis of wear profile and damages after the abrasion resistance tests using the pin on disc method, the optical profilometer was used.The surface texture morphology, wear profiles and defects of the countersample material were also made using confocal and stereoscopic Zeiss microscopes.

AFM atomic force microscope Park Systems XE-100 in a non-contact mode was used to LIPSS nanostructure researches. Results were determined by parameters describing the surface roughness: arithmetic average of ordinates profile (Ra), Rough Mean Square, $(\mathrm{RMS} / \mathrm{Rq})$, and sum of maximum height and maximum depth $(\Delta \mathrm{Z})$. 


\section{DISCUSSION OF RESEARCH RESULTS}

As a result of interaction of the laser high frequency pulses with the surface of tested tool materials, as expected, changes occurred in the morphology of surface layer. After solidification of melted surface, its microstructural and nanostructured special topography is created. As a result of evaporation of a part of tested material in the micro scale, so-called lubricant reservoirs spaced apart by a distance of around $20 \mu \mathrm{m}$ are created, while the microstructure special topography of this surface resembles the honeycomb structure (Figure 1).

a)

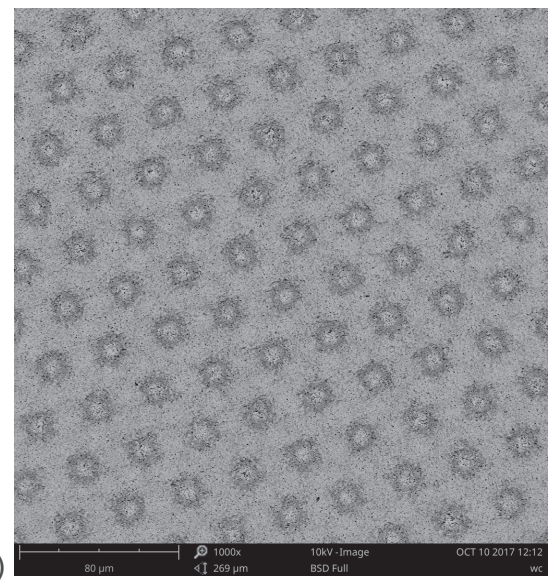

b)

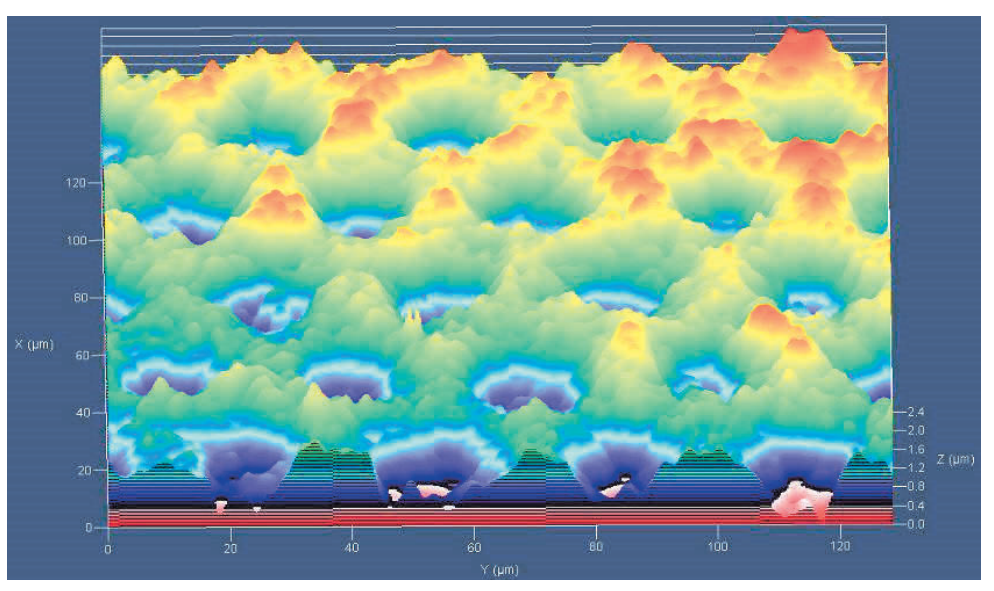

Figure 1 Laser microstructure on surface cemented carbides: a) view 2D, b) view 3D

In turn, in the nanostructure special topography of the examined surface, the occurrence of nanoripples called laser-induced periodic surface structures (LIPSS) were found. The resulting LIPSS nanoripples, both on the surface of cemented carbides, sialon ceramics and surface of the $\mathrm{Al}_{2} \mathrm{O}_{3}+\mathrm{TiN}$ coating, have the same periodicity equal to the laser wavelength. The height of the resulting nanoripples varies from 150 to $200 \mathrm{~nm}$, while the width of this periodic nanostructure for all test tool materials ranges from 200 to $400 \mathrm{~nm}$ (Figure 2).

a)

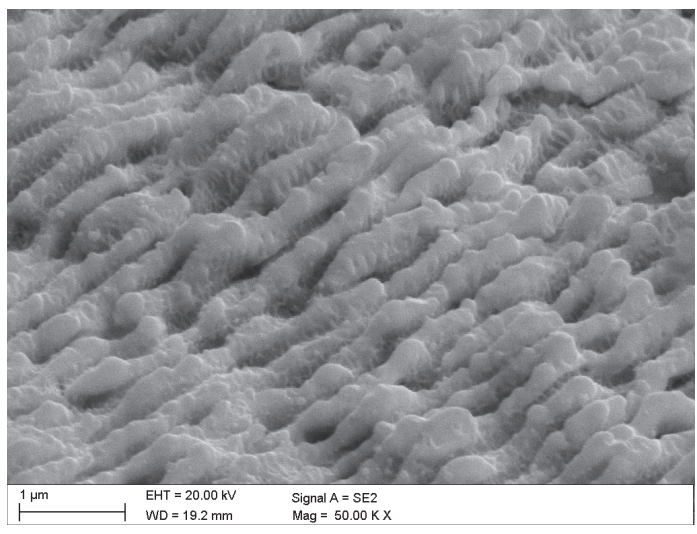

b)

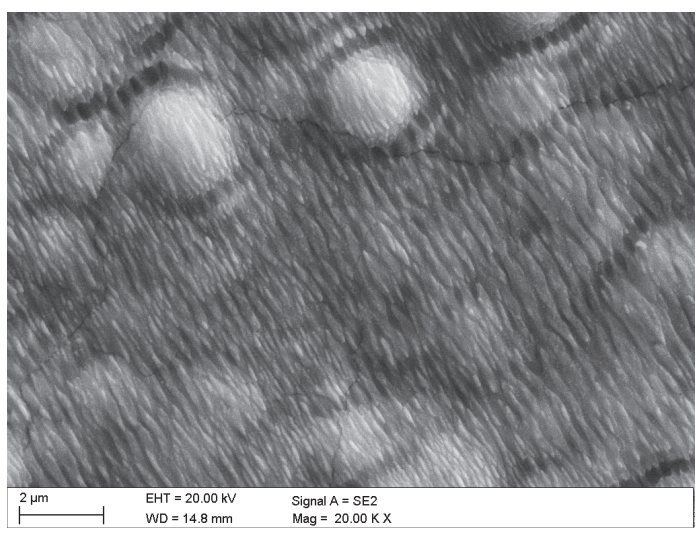

Figure 2 Nanoripples LIPSS: a) on surface cemented carbides, b) on surface of $\mathrm{Al}_{2} \mathrm{O}_{3}+\mathrm{TiN}$ coating

On the base of conducted tests, it was found that laser texturing significantly increases abrasion resistance of sintered tool materials as well as $\mathrm{Al}_{2} \mathrm{O}_{3}+\mathrm{TiN}$ coatings. Pin on disc test shows that significantly the width of trace is reduced and, in consequence, the loss of the volume of the wear material and the mass of a sample. The edges of traces of non-textured samples are irregular and frayed in comparison with regular edges shapes of the textured samples. The mechanism of damages that dominates during these tests is abrasive mechanism. It was also observed, that in case of sialon ceramics, there was a sticking of counter-sample material to edges 
of scratches, that is related to the occurrence in surface layer of this material micropores and microgaps (Figure 3).

a)

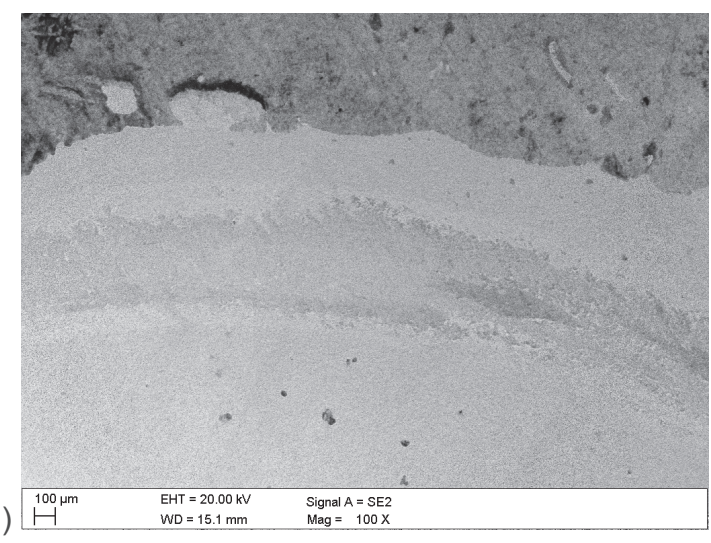

c)

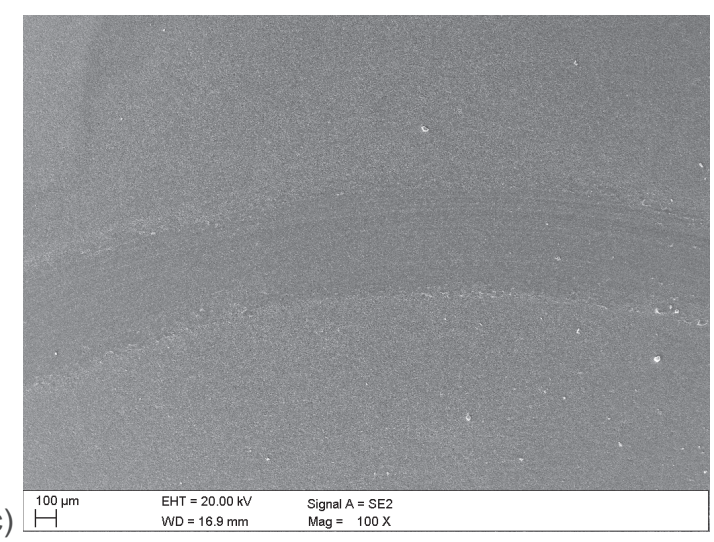

e)

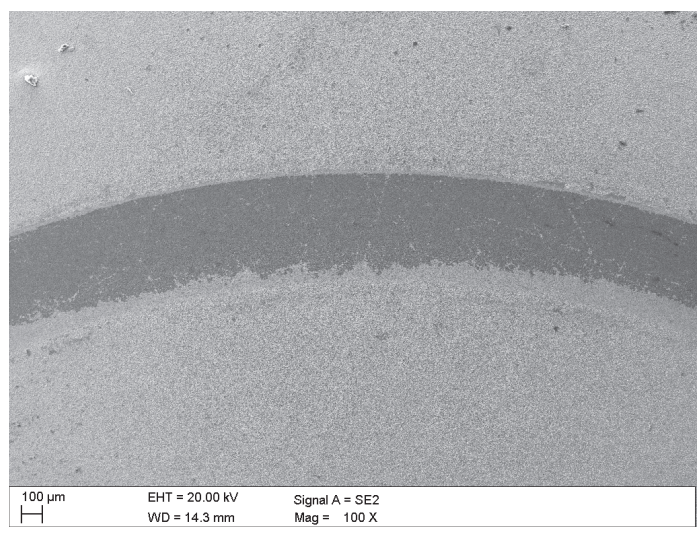

b)

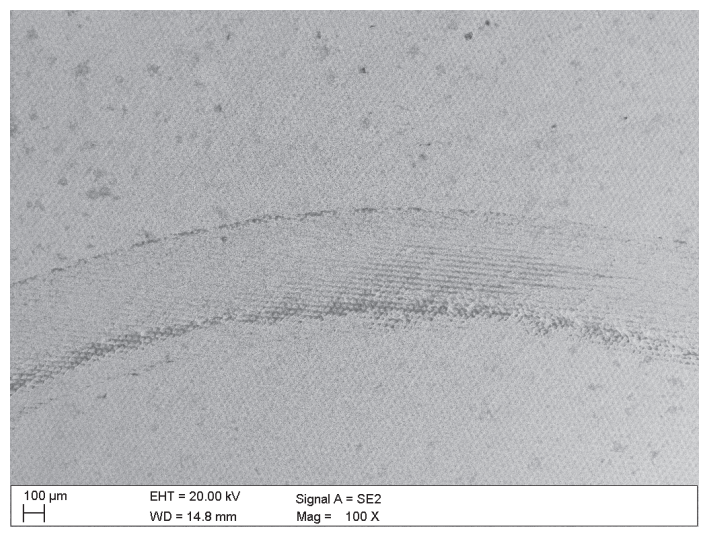

d)
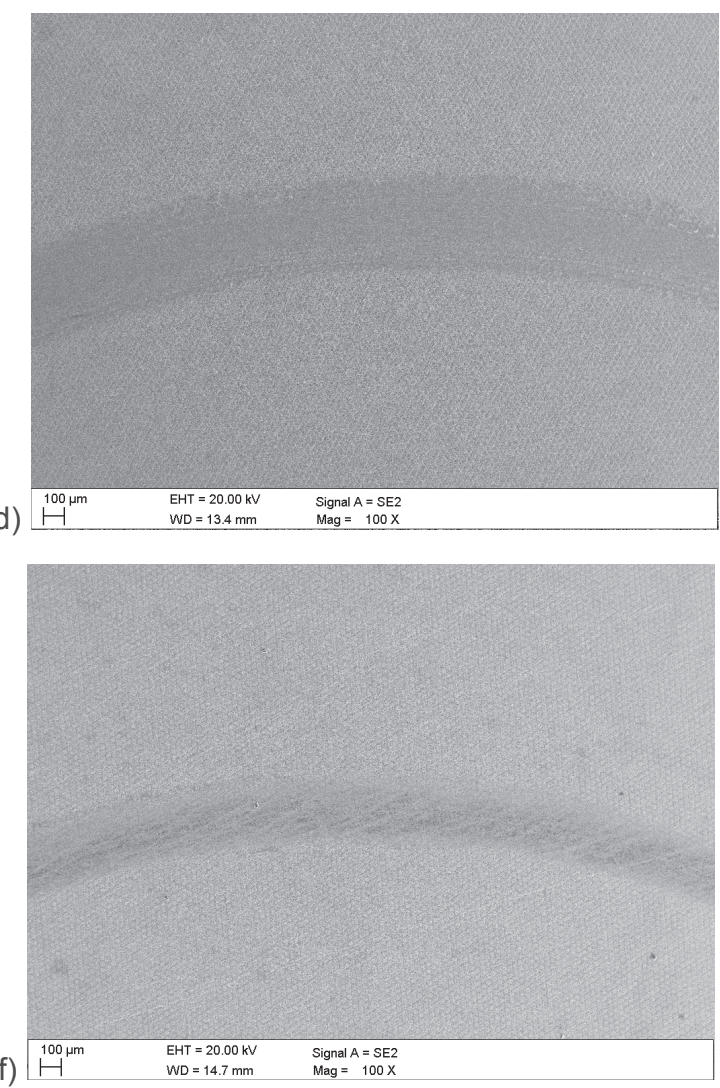

Figure 3 Trace of tribological wear on the surface of: a) cemented carbides before laser texturing, b) cemented carbides after laser texturing, c) sialon before laser texturing, d) sialon after laser texturing, e) $\mathrm{Al}_{2} \mathrm{O}_{3}+\mathrm{TiN}$ coating before laser texturing, f) $\mathrm{Al}_{2} \mathrm{O}_{3}+\mathrm{TiN}$ coating after laser texturing

Analyzing the wear profiles, it was found that the traces depth is significantly reduced for non-textured tool materials with an average of $2 \mu \mathrm{m}$ to $1 \mu \mathrm{m}$ for textured surfaces (Figures 4,5 ). The change in wear depth is closely related to microstructural and nanostructure special topography of textured surfaces. The textured surface reduces the contact area of tested material and anti-counter material. The reduction of contact area of tested system also has the influence on reducing the friction coefficient after laser texturing. On average, before laser texturing, the friction coefficient is stabilized up to 0.7 , while after texturing it reached a value of 0.4. Examples of friction coefficient diagram are shown in Figure 6. 


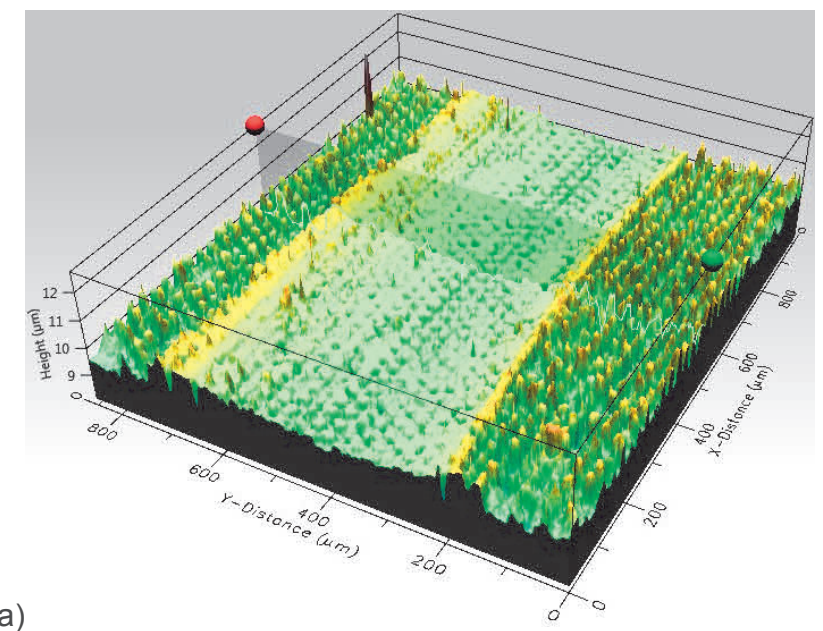

a)

Figure 4 Cross section profiles of cemented carbides wear during pin on disc test - after laser texturing: a) view $3 D$, b) line profile
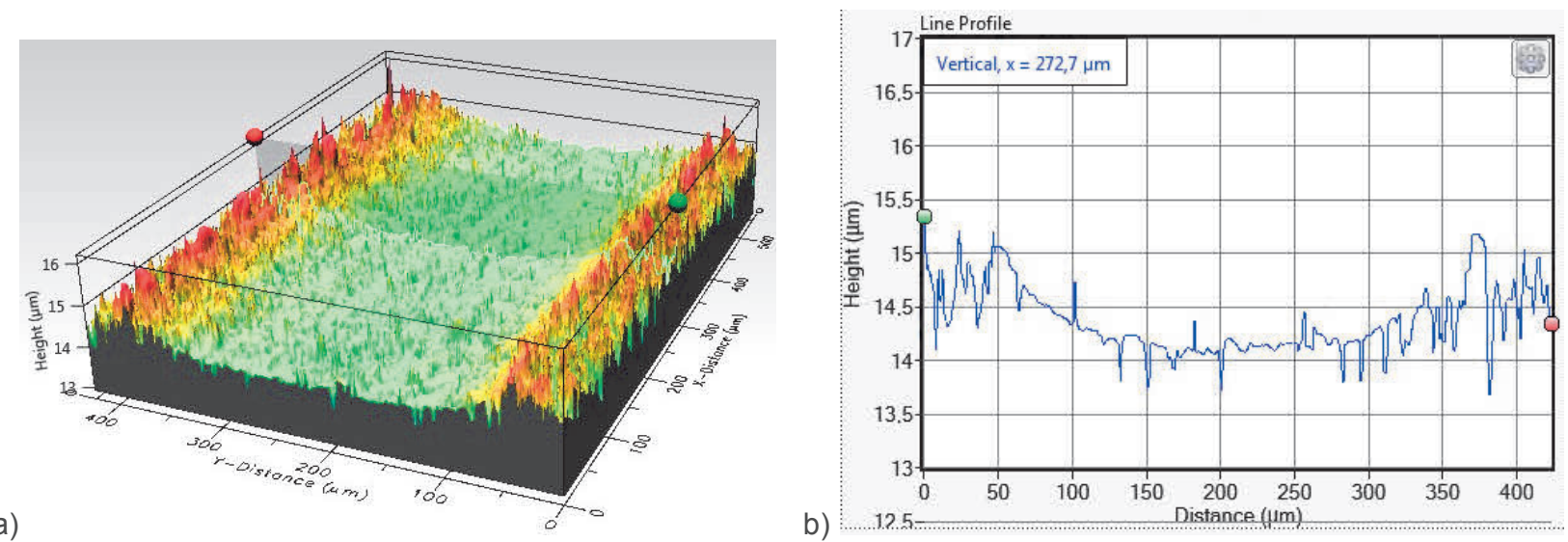

Figure 5 Cross section profiles of $\mathrm{Al}_{2} \mathrm{O}_{3}+\mathrm{TiN}$ coating wear during pin on disc test - after laser texturing: a) view $3 D, b)$ line profile

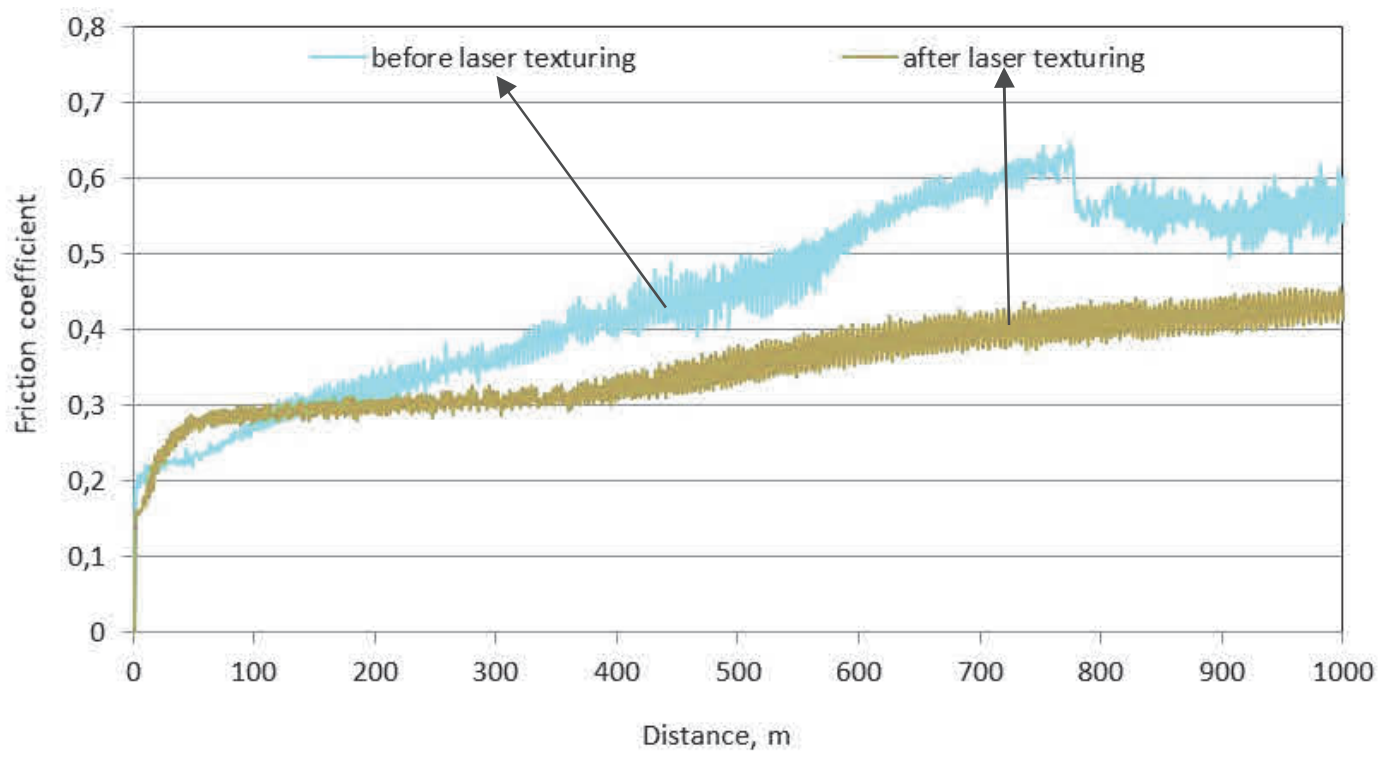

Figure 6 Diagram of friction coefficient according to the friction trace during the pin-on-disc test for sialon substrate - before and after laser texturing 


\section{CONCLUSION}

Despite of widespread use of ever-better CVD and PVD coatings deposited on tool materials, solutions are still being looking for that will increase the tool abrasion resistance. One of such solutions is the use of a regular texture obtained with the Nd: YVO4 neodymium laser on surfaces of non-coated tool materials as well as CVD coated materials. The improvement of abrasion resistance of tested surfaces of cemented carbides, sialon ceramics and $\mathrm{Al}_{2} \mathrm{O}_{3}+\mathrm{TiN}$ coating should be associated with obtaining a regular micro and nanometric structure of tool surface. Created texture reduces the contact surface in tribological system ensuring a reduction in friction coefficient. The abrasion of laser-textured surfaces in comparison to non-textured surfaces was smaller and more regular. The character of tool materials damages in tribological system is typical for abrasive mechanisms. The greatest improvement in abrasion resistance among tested materials was noted in the case of laser texturing of cemented carbide tools surface, for which the value of the friction coefficient is decreased by 0.2 .

\section{ACKNOWLEDGEMENTS}

The publication was co-financed by the statutory grant of the Faculty of Mechanical Engineering of the Silesian University of Technology in 2018.

\section{REFERENCES}

[1] STASZUK M., PAKUŁA D., CHLADEK G., PAWLYTA M., PANCIELEJKO M. and CZAJA P. Investigation of the structure and properties of PVD coatings and ALD plus PVD hybrid coatings deposited on sialon tool ceramics. Vacuum. 2018. vol. 153, pp. 184-190.

[2] PAKUŁA D., STASZUK M., GOŁOMBEK K., ŚLIWA A. and MIKUŁA J. Structure and properties of the tool ceramics with hard wear resistant coatings. Archives of Metallurgy and Materials. 2016. vol. 61, no. 3, pp. 1265-1270.

[3] STASZUK M., PAKUŁA D. and TAŃSKI T. Investigation studies involving wear resistant ALD/PVD hybrid coatings on sintered tool substrate. Materiali in Tehnologije / Materials and Technology. 2016. vol. 55, no. 5, pp. 755-759.

[4] ŚLIWA A., MIKUŁA J., GOŁOMBEK K., KWAŚNY W. and PAKUŁA D. Internal stresses in PVD coated tool composites. Archives of Metallurgy and Materials. 2016. vol. 61, no. 3, pp. 1371-1278.

[5] PAKUŁA D., STASZUK M., DZIEKOŃSKA M., KOŽMÍN P. and ČERMÁK A. Structure and properties of coating obtained by Chemical Vapour Deposition with the laser microstructuring. Vacuum. 2018. vol. 154, pp. 272-284.

[6] XING Y., DENG J., LI S., YUE H., MENG R. and GAO P. Cutting performance and wear characteristics of $\mathrm{Al}_{2} \mathrm{O}_{3} / \mathrm{TiC}^{2}$ ceramic cutting tools with WS2/Zr soft-coatings and nano-textures in dry cutting. Wear. 2014. vol. 318, pp. 12-26.

[7] JIANXIN D., YUNSONG L., ZE W. and YOUQIANG X. Performance of femtosecond laser-textured cutting tools deposited with WS 2 solid lubricant coatings. Surface \& Coatings Technology. 2013. vol. 222, pp. 135-143.

[8] ZHANG K., DENG J., DING Z., GUO X. and SUN L. Improving dry machining performance of TiAIN hard-coated tools through combined technology of femtosecond laser-textures and $\mathrm{WS}_{2}$ soft-coatings. Journal of Manufacturing Processes. 2017. vol. 30, pp. 492-501.

[9] KUMAR MISHRA S., GHOSH S. and ARAVINDAN S. 3D finite element investigations on textured tools with different geometrical shapes for dry machining of titanium alloys. International Journal of Mechanical Sciences. 2018. vol. 141, pp. 424-449.

[10] SUGIHARA T., ENEMOTO T. Crater and flank wear resistance of cutting tools having micro textured surfaces. Precision Engineering. 2013. vol. 37/4, pp. 888-896.

[11] ENEMOTO T., SUGIHARA T., YUKINAGA S., HIROSE K. and SATAKE U. Highly wear-resistant cutting tools with textured surfaces in steel cutting. CIRP Annals - Manufacturing Technology. 2012. vol. 61, no. 1, pp. 571-574.

[12] NEVES D., DINIZ A.E. and LIMA M.S.F. Microstructural analyses and wear behavior of the cemented carbides tools after laser surface treatment and PVD coating. Applied Surface Science. 2013. vol. 282, pp. 680-688. 